Subscriber access provided by Caltech Library

\title{
Article
}

\section{Promoter effects of alkali metal cations on the electrochemical reduction of carbon dioxide}

Joaquin Resasco, Leanne D. Chen, Ezra Clark, Charlie Tsai, Christopher Hahn, Thomas F. Jaramillo, Karen Chan, and Alexis T. Bell

J. Am. Chem. Soc., Just Accepted Manuscript • DOI: 10.1021/jacs.7b06765 • Publication Date (Web): 24 Jul 2017

Downloaded from http://pubs.acs.org on July 26, 2017

\section{Just Accepted}

"Just Accepted" manuscripts have been peer-reviewed and accepted for publication. They are posted online prior to technical editing, formatting for publication and author proofing. The American Chemical Society provides "Just Accepted" as a free service to the research community to expedite the dissemination of scientific material as soon as possible after acceptance. "Just Accepted" manuscripts appear in full in PDF format accompanied by an HTML abstract. "Just Accepted" manuscripts have been fully peer reviewed, but should not be considered the official version of record. They are accessible to all readers and citable by the Digital Object Identifier (DOI®). "Just Accepted" is an optional service offered to authors. Therefore, the "Just Accepted" Web site may not include all articles that will be published in the journal. After a manuscript is technically edited and formatted, it will be removed from the "Just Accepted" Web site and published as an ASAP article. Note that technical editing may introduce minor changes to the manuscript text and/or graphics which could affect content, and all legal disclaimers and ethical guidelines that apply to the journal pertain. ACS cannot be held responsible for errors or consequences arising from the use of information contained in these "Just Accepted" manuscripts. 


\title{
Promoter effects of alkali metal cations on the electrochemical reduction of carbon dioxide
}

\author{
Joaquin Resasco ${ }^{1,2}$, Leanne D. Chen ${ }^{3,4,5}$, Ezra Clark ${ }^{1,2}$, Charlie Tsai ${ }^{3,4}$ Christopher Hahn ${ }^{3,4}$, Thomas F. \\ Jaramillo $^{3,4}$, Karen Chan ${ }^{3,4}$, and Alexis T. Bell ${ }^{1,2} *$ \\ 1. Department of Chemical Engineering, University of California, Berkeley, CA 94720 \\ 2. Joint Center for Artificial Photosynthesis, Material Science Division, Lawrence Berkeley National \\ Laboratory, Berkeley, CA 94720 \\ 3. SUNCAT Center for Interface Science and Catalysis, Department of Chemical Engineering, Stanford \\ University, Stanford, CA 94305 \\ 4. SUNCAT Center for Interface Science and Catalysis, SLAC National Accelerator Laboratory, Menlo \\ Park, CA 94025 \\ 5. Present Address: Division of Chemistry and Chemical Engineering, California Institute of Technology, \\ Pasadena, CA 91125 \\ Submitted to \\ Journal of the American Chemical Society \\ March 7, 2017 \\ *To whom correspondence should be addressed: alexbell@,berkeley.edu
}




\section{Abstract}

The electrochemical reduction of $\mathrm{CO}_{2}$ is known to be influenced by the identity of the alkali metal cation in the electrolyte; however, a satisfactory explanation for this phenomenon has not been developed. Here we present the results of experimental and theoretical studies aimed at elucidating the effects of electrolyte cation size on the intrinsic activity and selectivity of metal catalysts for the reduction of $\mathrm{CO}_{2}$. Experiments were conducted under conditions where the influence of electrolyte polarization is minimal in order to show that cation size affects the intrinsic rates of formation of certain reaction products, most notably for $\mathrm{HCOO}^{-}, \mathrm{C}_{2} \mathrm{H}_{4}$, and $\mathrm{C}_{2} \mathrm{H}_{5} \mathrm{OH}$ over $\mathrm{Cu}(100)$ - and $\mathrm{Cu}(111)$-oriented thin films, and for $\mathrm{CO}$ and $\mathrm{HCOO}^{-}$over polycrystalline $\mathrm{Ag}$ and $\mathrm{Sn}$. Interpretation of the findings for $\mathrm{CO}_{2}$ reduction was informed by studies of the reduction of glyoxal and CO, key intermediates along the reaction pathway to final products. Density functional theory calculations show that the alkali metal cations influence the distribution of products formed as a consequence of electrostatic interactions between solvated cations present at the outer Helmholtz plane and adsorbed species having large dipole moments. The observed trends in activity with cation size are attributed to an increase in the concentration of cations at the outer Helmholtz plane with increasing cation size.

Keywords: Electrochemical reduction, $\mathrm{CO}_{2}$, copper, silver 


\section{Introduction}

The electrochemical reduction of $\mathrm{CO}_{2}$ offers a means for storing electrical energy produced by renewable but intermittent resources, such as wind and solar radiation. ${ }^{1,2}$ Hydrocarbons and alcohols, rather than carbon monoxide and formic acid, are the preferred products of $\mathrm{CO}_{2}$ reduction because of their high energy density. Despite extensive efforts aimed at identifying electrocatalysts that can produce these products, copper $(\mathrm{Cu})$ remains the only material capable of doing so with significant yields. ${ }^{3-5}$ Nevertheless, $\mathrm{Cu}$ requires a high overpotential ( $-1 \mathrm{~V}$ versus RHE) and produces a broad spectrum of products. ${ }^{6,7}$ Clearly, the discovery of novel means for reducing $\mathrm{CO}_{2}$ to desirable products with higher efficiency and selectivity is needed. To do so requires understanding the fundamental processes occurring at the electrode surface. In addition to metal-adsorbate interactions, a full description of electrochemical reactions must include the effects of solvation and interfacial electric fields. A number of studies have shown that one way of influencing the product distribution is through changes in the electrolyte cation. ${ }^{8-13}$

The role of cations is particularly interesting because a number of studies have shown that both the activity and selectivity of $\mathrm{Ag}, \mathrm{Hg}$, and $\mathrm{Cu}$ for the $\mathrm{CO}_{2}$ reduction reaction $\left(\mathrm{CO}_{2} \mathrm{RR}\right)$ are influenced significantly by the size of the alkali metal cation in the electrolyte. ${ }^{8-13}$ Similar effects have also been observed for the electrochemical reduction of oxygen, the oxidation of hydrogen, and the oxidation of low molecular weight alcohols. ${ }^{14-18}$ For $\mathrm{Ag}$ and $\mathrm{Hg}$, which are selective for $\mathrm{CO}_{2}$ reduction to carbon monoxide (CO) and formate anions ( $\left.\mathrm{HCOO}^{-}\right)$, respectively, increasing the alkali metal cation size increases the rates of formation of these products. ${ }^{8,10,11}$ For $\mathrm{Cu}$, increasing alkali metal size leads to higher selectivities to $\mathrm{C}_{2}$ products, e.g., ethylene and ethanol. ${ }^{9,12,13}$ Explanations for these phenomena have been attributed to differences in local $\mathrm{pH}$, or differences in kinetic overpotentials due to the electrochemical potential in the outer Helmholtz plane being affected by cation size. ${ }^{8,10,11,13}$ 
One of the challenges to finding a consistent interpretation for the effects of cation size on the intrinsic kinetics of $\mathrm{CO}_{2}$ reduction is that many studies are carried out under conditions where mass transport also contributes to the observed activity and product distribution. In recent study, we reported the effects of cation size on the rate of the $\mathrm{CO}_{2} \mathrm{RR}$ under strong mass-transport limitations. ${ }^{13}$ We showed that the increase in $\mathrm{pH}$ and the decrease in $\mathrm{CO}_{2}$ concentration near the cathode, caused by inadequate mass transfer through the hydrodynamic boundary layer in front of the cathode, could be offset by the hydrolysis of solvated cations. We showed that the increased buffering effect of solvated cations with cation size could be captured theoretically and suggested that this effect is responsible for the observed changes in the overall current density and the distribution of product current densities with cation size.

In this work, we present a combined experimental and theoretical study of the effects of electrolyte cation size on the intrinsic activity and selectivity of metal catalysts for the reduction of $\mathrm{CO}_{2}$. In contrast to earlier studies, experiments were conducted at sufficiently low applied voltages to avoid the effects of concentration polarization of the electrolyte, so that the influence of cation size on the intrinsic activity and selectivity of each catalyst could be observed. Most of our work was conducted using epitaxially grown $\mathrm{Cu}(100)$ or $\mathrm{Cu}(111)$ thin films; a more limited study was carried out using polycrystalline Ag and Sn films. Density functional theory (DFT) calculations were used to investigate how cations and cation size affect the stabilization of reaction intermediates involved in the reduction of $\mathrm{CO}_{2}$. These calculations demonstrate that adsorbed species with large dipole moments oriented away from the solvent are stabilized by electrostatic interactions with solvated cations, while trends in activity with cation size arise from differences in ion concentration at the Helmholtz plane.

\section{Methods}

Electrode Preparation 
Single-side polished $\operatorname{Si}(100)$ or (110) wafers (Virginia semiconductor, 1-10 $\Omega \mathrm{cm}$ ) were diced into $\sim 4 \mathrm{~cm}^{2}$ sized pieces that were then used as electrode substrates. Prior to $\mathrm{Cu}$ deposition, the native oxide was removed from the $\mathrm{Si}$ substrates by submerging them in a $10 \% \mathrm{HF}$ solution for $5 \mathrm{~min}$. Immediately after HF etching, the Si pieces were transferred to a vacuum chamber for sputter deposition of $\mathrm{Cu}$ in an AJA ATC Orion-5 sputtering system. The base pressure of the sputtering system prior to deposition was $\sim 2 \times 10^{-7}$ torr. The flow rate of the sputtering gas (Ar) was $25 \mathrm{sccm}$ and the sputtering pressure was adjusted to $2 \times 10^{-3}$ torr by controlling the speed at which the chamber was pumped, using a variable butterfly valve. $\mathrm{Cu}(99.999 \%$ Kurt Lesker) was deposited at a rate of $1 \AA / \mathrm{s}$, as determined by a calibrated quartz crystal monitor, at ambient temperature. The total film thickness deposited was $100 \mathrm{~nm}$. Polished, polycrystalline foils of Ag and Sn (99.99\% Alfa Aesar) were also used as electrodes without further preparation.

\section{Electrode Characterization}

The structure of the $\mathrm{Cu}$ thin films was characterized by X-ray diffraction. The orientation and epitaxial quality of the films were determined using symmetric $\theta-2 \theta$ scans, in plane $\phi$ scans, $\omega$ scans or rocking curves, and pole figures. XRD patterns were taken with a PANanalytical X'Pert diffractometer, which uses a $\mathrm{Cu} \operatorname{K} \alpha(\lambda=1.54056 \AA)$ X-ray source. Symmetric $\theta-2 \theta$ scans were collected on samples fixed onto a flat glass slide in locked-coupled mode with a goniometer resolution of $0.001^{\circ}$. Measured diffraction patterns were compared to known standards taken from the International Center for Diffraction Data (ICDD) PDF4 database (card \#71-4610 for Cu).

\section{Electrochemical Measurements}

All electrochemical experiments were conducted in a gas-tight electrochemical cell machined from polyether ether ketone (PEEK). ${ }^{19}$ The cell was cleaned with 20 wt. \% nitric acid and oxidized in UV-generated ozone for 15 min prior to the initiation of an experiment. The working and counter electrodes were parallel and separated by an anion-conducting membrane (Selemion AMV AGC Inc.). A gas dispersion frit was incorporated into the cathode chamber to provide vigorous electrolyte mixing. The exposed geometric surface area of each electrode was $1 \mathrm{~cm}^{2}$ and the electrolyte volume of each electrode 
chamber was $1.8 \mathrm{~mL}$. The counter electrode was a Pt foil (99.9\% Sigma Aldrich) that was flame annealed prior to each experiment. The working electrode potential was referenced against an $\mathrm{Ag} / \mathrm{AgCl}$ electrode (Innovative Instruments Inc.) that was calibrated against a homemade standard hydrogen electrode (SHE). $0.05 \mathrm{M} \mathrm{M}_{2} \mathrm{CO}_{3}$ (M referring to an alkali metal cation) solutions were prepared by mixing ultra-pure salts (Sigma Aldrich 99.995\%) and 18.2 M $\Omega \mathrm{DI}$, and were used as the electrolyte without further purification. The cathode chamber was sparged with $\mathrm{CO}_{2}(99.999 \%$ Praxair $)$ at a rate of $5 \mathrm{sccm}$ for 20 min prior to and throughout the duration of all electrocatalytic measurements. Upon saturation with $\mathrm{CO}_{2}$ the $\mathrm{pH}$ of the electrolyte was 6.8 , which was maintained throughout the duration of electrolysis.

Electrochemical measurements were performed using a Biologic VSP-300 potentiostat. All electrochemical data were recorded versus the reference electrode and converted to the RHE scale. Potentiostatic electrochemical impedance spectroscopy (PEIS) was used to determine the uncompensated resistance $\left(\mathrm{R}_{\mathrm{u}}\right)$ of the electrochemical cell by applying voltage waveforms about the open circuit potential with an amplitude of $20 \mathrm{mV}$ and frequencies ranging from $50 \mathrm{~Hz}$ to $500 \mathrm{kHz}$. The potentiostat compensated for $85 \%$ of $\mathrm{R}_{\mathrm{u}}$ in situ and the last $15 \%$ was post-corrected to arrive at accurate potentials. The electrocatalytic activity was assessed by conducting chronoamperometry at each fixed applied potential for $70 \mathrm{~min}$.

Product Analysis

The effluent from the electrochemical cell was passed through the sampling loop $(250 \mu \mathrm{L})$ of an Agilent 7890B gas chromatograph equipped with a pulsed-discharge helium ionization detector (PDHID). He (99.9999\% Praxair) was used as the carrier gas. The effluent of the electrochemical cell was sampled every $14 \mathrm{~min}$. The gaseous products were separated using a Hayesep-Q capillary column (Agilent) connected in series with a packed ShinCarbon ST column (Restek Co.). The column oven was maintained at $50{ }^{\circ} \mathrm{C}$ for $1 \mathrm{~min}$ followed by a temperature ramp at $30{ }^{\circ} \mathrm{C} / \mathrm{min}$ to $250{ }^{\circ} \mathrm{C}$, which was maintained for the duration of the analysis. The signal response of the PDHID to each gaseous product was calibrated by analyzing a series of NIST-traceable standard gas mixtures (Air Gas). 
The electrolyte from both electrode chambers was collected after electrolysis and analyzed using a Thermo Scientific UltiMate 3000 liquid chromatograph equipped with a refractive index detector (RID). The electrolyte aliquots were stored in a refrigerated autosampler until analyzed in order to minimize the evaporation of volatile products. The liquid-phase products contained in a $10 \mu \mathrm{L}$ sample were separated using a series of two Aminex HPX 87-H columns (Bio-Rad) and a $1 \mathrm{mM}$ sulfuric acid eluent (99.999\% Sigma Aldrich). The column oven was maintained at $60{ }^{\circ} \mathrm{C}$ for the duration of the analysis. The signal response of the RID to each liquid-phase product was calibrated by analyzing standard solutions of each product at a concentration of 1,10 , and $50 \mathrm{mM}$.

\section{Theoretical Calculations}

Plane-wave density functional theory (DFT) employing periodic boundary conditions was used for all calculations in this study. The Quantum ESPRESSO ${ }^{20}$ code and the Atomic Simulation Environment $(\mathrm{ASE})^{21}$ were used, along with ultrasoft pseudopotentials and the Bayesian error estimation exchange-correlation functional with van der Waals interactions (BEEF-vdW). ${ }^{22}$ This functional has been optimized for both chemisorption energies and long-range van der Waals interactions. For all calculations, a plane-wave cutoff of $500 \mathrm{eV}$ and a density cutoff of $5000 \mathrm{eV}$ were used, based on convergence tests from previous studies. ${ }^{23}$ A Monkhorst-Pack ${ }^{24} k$-point grid of $(4 \times 4 \times 1)$ was used for $(3 \times 3)$ cells while a $(2 \times 2 \times 1)$ grid was used for $(6 \times 6)$ cells. All systems were modeled using a periodic $\mathrm{Cu}(111)$ slab, two ice-like water bilayers, the solvated ion and at least $12 \AA$ of vacuum perpendicular to the surface. The field effect on various $\mathrm{CO}_{2}$ adsorbates without ions or solvating waters was also investigated by applying a sawtooth potential in each simulation cell, for moderate field strengths where the vacuum energy remains above the Fermi level. ${ }^{25}$ As an example, Figure S3 in the Supporting Information (SI) shows the average potential energy along the $z$-direction for $\mathrm{CH}_{3}$ on $\mathrm{Cu}(111)$, with an applied sawtooth potential.

Constrained minima hopping ${ }^{26}(\mathrm{CMH})$ was used for the global optimization of water structures surrounding each solvated ion. $\mathrm{CMH}$ enforces molecular identity by constraining the atomic distances 
within each molecular entity through Hookean constraints. The atoms are thermalized in a MaxwellBoltzmann distribution at an initial temperature of $1000 \mathrm{~K}$, then evolved through molecular dynamics and relaxed to locate new local minima. To save computational cost, $\mathrm{CMH}$ was performed on two layers of $\mathrm{Cu}$. The $\mathrm{Cu}$ atoms were fixed, while all others were allowed to relax. The convergence criterion for the $\mathrm{CMH}$ was satisfied when three successive lowest energy minima were found within $0.05 \mathrm{eV}$ of each other. Thereafter, the system was relaxed until the forces on all atoms were less than $0.05 \mathrm{eV} / \AA$. Finally, the third layer of $\mathrm{Cu}$ was added back into the system to perform a single point calculation and obtain a more accurate value for the energy.

\section{Results}

Cation effects on $\mathrm{Cu}(100)$ and $\mathrm{Cu}(111)$ oriented films

a

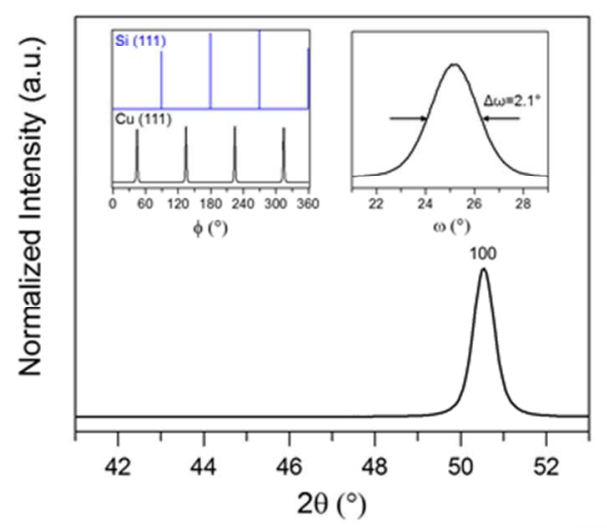

C

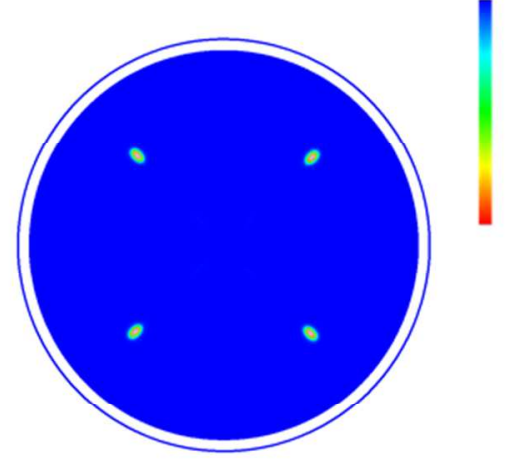

b

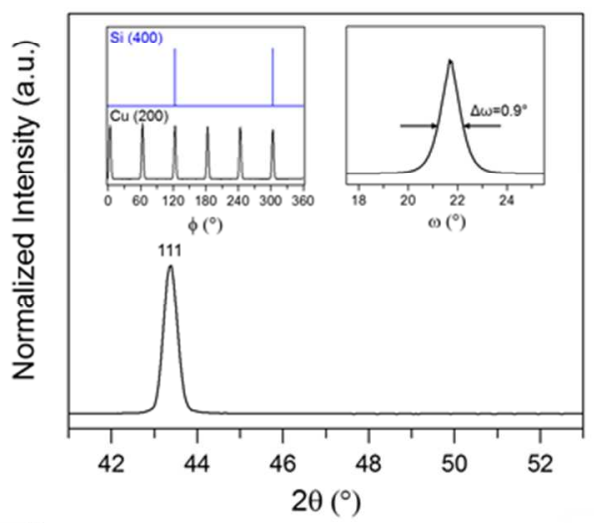

d

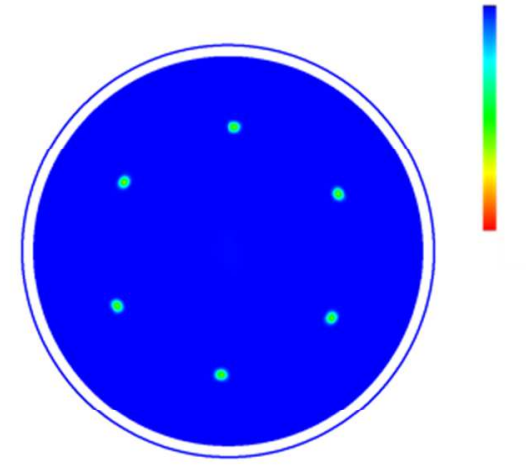


Figure 1: Structural characterization of oriented $\mathrm{Cu}$ thin films. a) Symmetric $\theta-2 \theta$, in plane $\phi$, and $\omega$ rocking curve scans for $\mathrm{Cu}$ deposited on $\mathrm{Si}(100)$. b) Symmetric $\theta-2 \theta$, in plane $\phi$, and $\omega$ rocking curve scans for $\mathrm{Cu}$ deposited on $\mathrm{Si}(110)$. c) $\mathrm{Cu}(111)$ pole figure for $\mathrm{Cu}$ deposited on $\mathrm{Si}(100)$. d) $\mathrm{Cu}(200)$ pole figure for $\mathrm{Cu}$ deposited on $\mathrm{Si}(110)$.

Epitaxially grown $\mathrm{Cu}$ thin films were used as electrocatalysts in order to have well-defined catalytic surfaces. ${ }^{27}$ These films were prepared by radio-frequency sputtering of $\mathrm{Cu}$ onto silicon (Si) single crystal substrates, taking advantage of the epitaxial relationship between $\mathrm{Cu}$ and $\mathrm{Si}$ substrates of different orientations. ${ }^{27-28}$ Most of our studies were conducted on the $\mathrm{Cu}(100)$ surface because it has been shown that polycrystalline $\mathrm{Cu}$ consists mostly of (100) oriented crystallites and the $\mathrm{Cu}(100)$ surface has a higher selectivity to more desirable products such as $\mathrm{C}_{2+}$ hydrocarbons and oxygenates (e.g., ethylene and ethanol). ${ }^{29-32}$ Symmetric $\theta-2 \theta$ XRD patterns of $100 \mathrm{~nm}$ thick $\mathrm{Cu}$ films deposited on $\mathrm{Si}(100)$ and $\mathrm{Si}(110)$ substrates are shown in Figure 1. The observation of a single $\mathrm{Cu}(200)$ diffraction peak for $\mathrm{Cu}$ deposited on $\mathrm{Si}(100)$ indicates that the film is oriented with the (100) crystallographic direction normal to the film plane. Similarly, for $\mathrm{Cu}$ deposited on $\mathrm{Si}(110)$ only the diffraction peak associated with $\mathrm{Cu}(111)$ is observed. ${ }^{27-28}$ While symmetric XRD scans establish the out-of-plane texture relationships, both out-ofplane and in-plane texture analyses are necessary to determine whether the $\mathrm{Cu}$ thin films grow epitaxially on $\mathrm{Si}$, as a film with strong fiber texture would show a similar diffraction pattern. To this end, in planetexture analysis was conducted using X-ray pole figures. Pole figures represent the texture of a material and show the distribution of particular crystallographic directions in a stereographic projection. The $\mathrm{Cu}(111)$ X-ray pole figure for $\mathrm{Cu}(100)$ on $\mathrm{Si}(100)$ exhibits discrete Bragg reflections, indicating cube-oncube epitaxial growth of $\mathrm{Cu}$ on the $\mathrm{Si}(100)$ substrate. Four-fold symmetry is observed for the $\mathrm{Cu}(111)$ Bragg reflections with an azimuthal angle of $90^{\circ}$ apart, which is expected for a $\mathrm{Cu}(100)$ single-crystal. For $\mathrm{Cu}$ (111) on Si (110), six-fold symmetry is observed for the $\mathrm{Cu}$ (200) Bragg reflections, indicating both strong out-of-plane and in-plane texture and thus epitaxial growth on the $\mathrm{Si}(110)$ substrate (Figure 1a). Six diffraction spots in the pole figure are seen instead of three because there are two discrete sets of crystallites from twinning with an azimuthal angle of $60^{\circ}$ apart. These results demonstrate that $\mathrm{Cu}$ thin films can be grown epitaxially with both (100) and (111) orientations. 

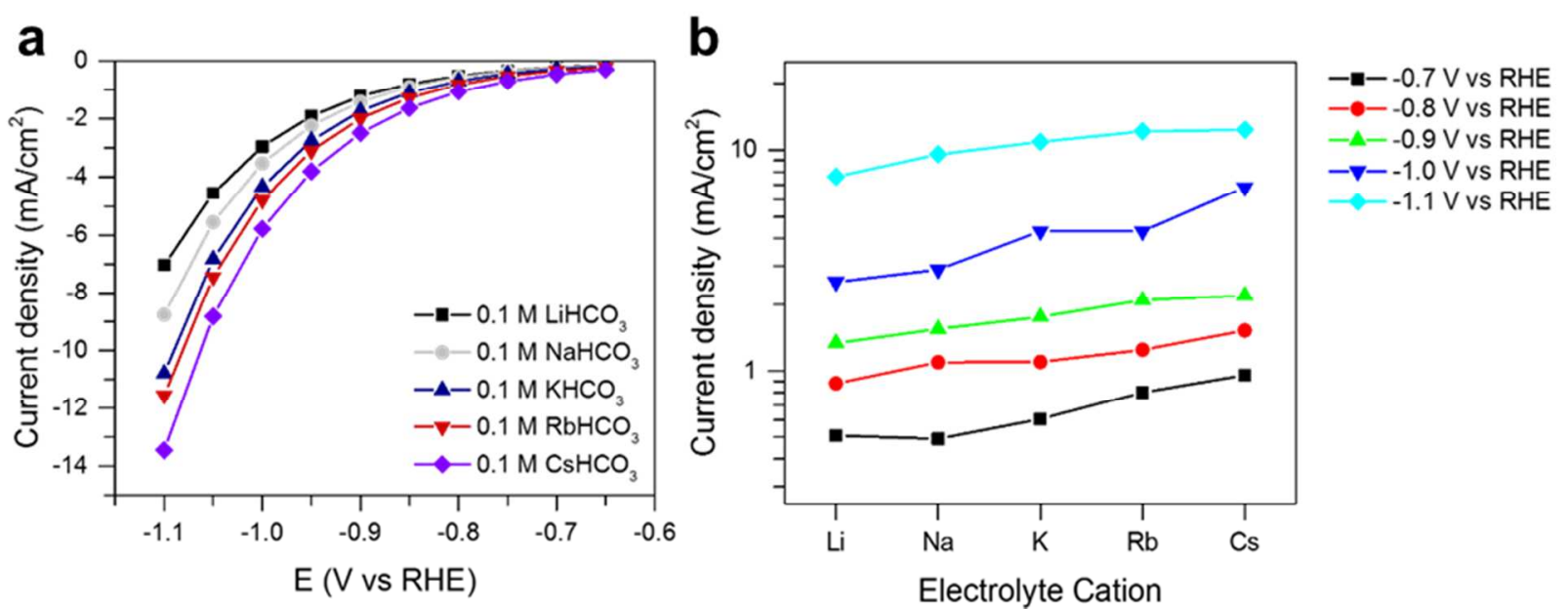

Figure 2: Effect of alkali metal cations on the total activity over $\mathrm{Cu}(100)$. a) Linear sweep voltammograms for $\mathrm{CO}_{2}$ reduction on $\mathrm{Cu}(100)$ in $\mathrm{CO}_{2}$ saturated $0.1 \mathrm{M}$ bicarbonate electrolytes containing different metal cations. b) Average current densities obtained during bulk electrolysis as a function of metal cation at different potentials.

The steady state activity and selectivity of the $\mathrm{Cu}(100)$ surface was investigated in $\mathrm{CO}_{2}$-saturated bicarbonate electrolytes containing different alkali metal cations, by using potentiometric electrolysis at potentials from -0.7 to $-1.1 \mathrm{~V}$ vs the reversible hydrogen electrode (RHE). Figure 2 shows the total current density as a function of electrolyte cation at various potentials. From both steady state potentiostatic and potential sweep measurements, it is clear that the total current density increases with cation size, and this trend is observed at all applied potentials. To identify the contributions to the increase in the total current density, we examined the effects of cation size on the product distribution. As large differences in total current density exist for electrolytes containing different cations, partial currents provide a better representation of trends in product formation rates than faradaic efficiencies. Complete information regarding faradaic efficiencies can be found in the supplementary information (Figure S1, Table S1). 
a

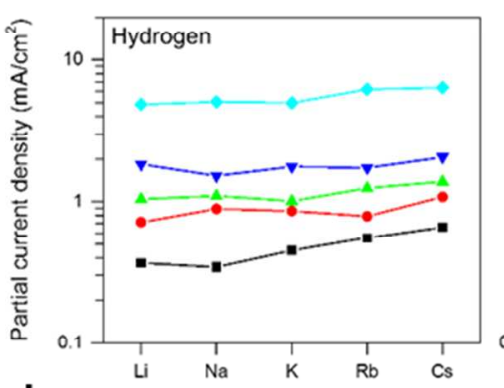

d

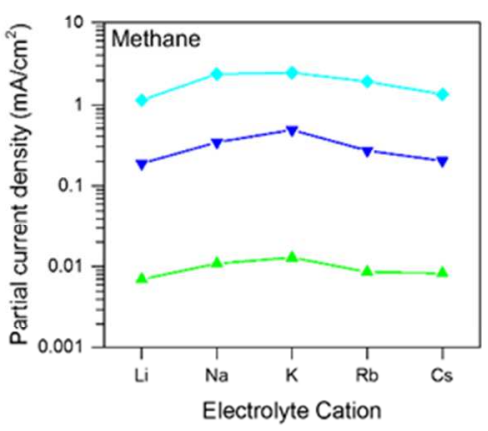

b

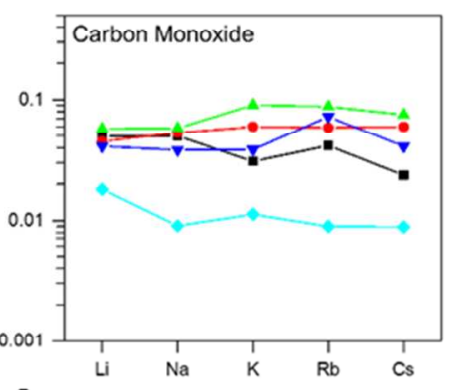

e

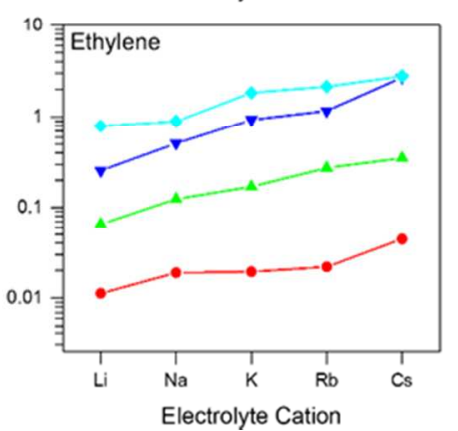

c

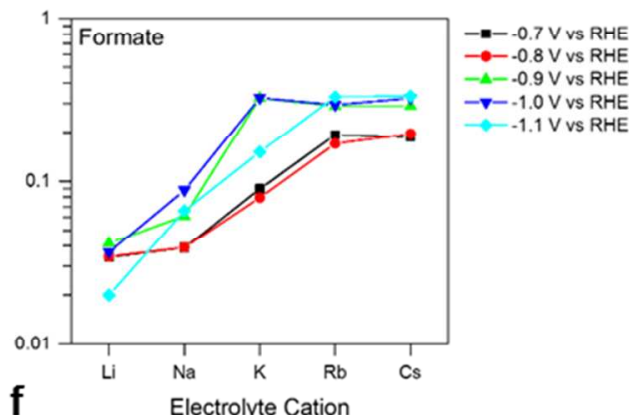

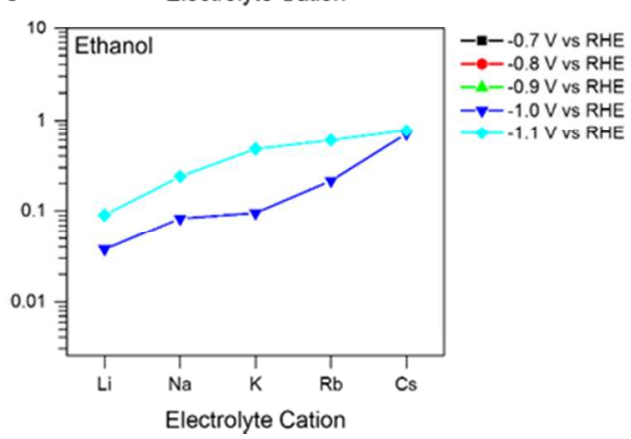

Figure 3: Cation effect on the rates of formation of major products of $\mathrm{CO}_{2}$ reduction over $\mathrm{Cu}(100)$. Partial current densities for each of the major products as a function of the electrolyte metal cation on $\mathrm{Cu}(100)$. Data are presented at potential between -0.7 to $-1.1 \mathrm{~V}$ vs RHE.

Figure 3 shows the partial current density for each of the major products as a function of electrolyte cation. Formation rates of minor liquid products can be found in the supplementary information (Table S1). A key finding is that the production rates of hydrogen and carbon monoxide are relatively unaffected by increasing cation size, whereas the rates of formate, ethylene, and ethanol formation increase monotonically with increasing cation size. The rate of methane production reaches a maximum for $\mathrm{Na}^{+}$- and $\mathrm{K}^{+}$- based electrolytes and is lower in all other electrolytes. The trends seen in Fig. 3 are consistent with previous amperometric measurements. ${ }^{9}$ It is notable that these trends are independent of the applied overpotential.

To probe the effects of mass transport limitations, the $\mathrm{CO}_{2}$ flow rate into the electrochemical cell was varied. As the $\mathrm{CO}_{2}$ flow rate is increased, the hydrodynamic boundary layer thickness will decrease, resulting in a larger maximum diffusive flux of $\mathrm{CO}_{2}$ to the electrode surface. At low reaction rates (i.e., 
low current densities), for which diffusion of $\mathrm{CO}_{2}$ is sufficiently rapid to prevent depletion at the cathode surface, increasing the flowrate of $\mathrm{CO}_{2}$ should have no effect on catalyst activity. Whereas under mass transport limited conditions, increased reactant availability will affect the product distribution measured. ${ }^{13,32}$ Figure 4 shows that doubling the $\mathrm{CO}_{2}$ flow rate from 5 to $10 \mathrm{sccm}$ has no impact on the measured selectivity or activity of $\mathrm{Cu}(100)$ at $-0.9 \mathrm{~V}$ vs RHE and $-1.0 \mathrm{~V}$ vs RHE. However, at $-1.1 \mathrm{~V}$ vs RHE, doubling the $\mathrm{CO}_{2}$ flowrate decreases the faradic efficiency to $\mathrm{H}_{2}$ and $\mathrm{CH}_{4}$ and increases the faradaic efficiency for $\mathrm{C}_{2+}$ products. As shown previously, these trends are due to the increased rate of mass transfer at higher gas flowrates, which improves the supply of $\mathrm{CO}_{2}$ to the cathode. ${ }^{32}$ Therefore, the effects of cation size on the partial current densities observed in Figure 3 at potentials more positive than $\sim-1.0$ V vs RHE are ascribable to the influence of cation size on the intrinsic kinetics of $\mathrm{Cu}(100)$, particularly for the formation of formate, ethylene, and ethanol, and to a lesser degree, methane.

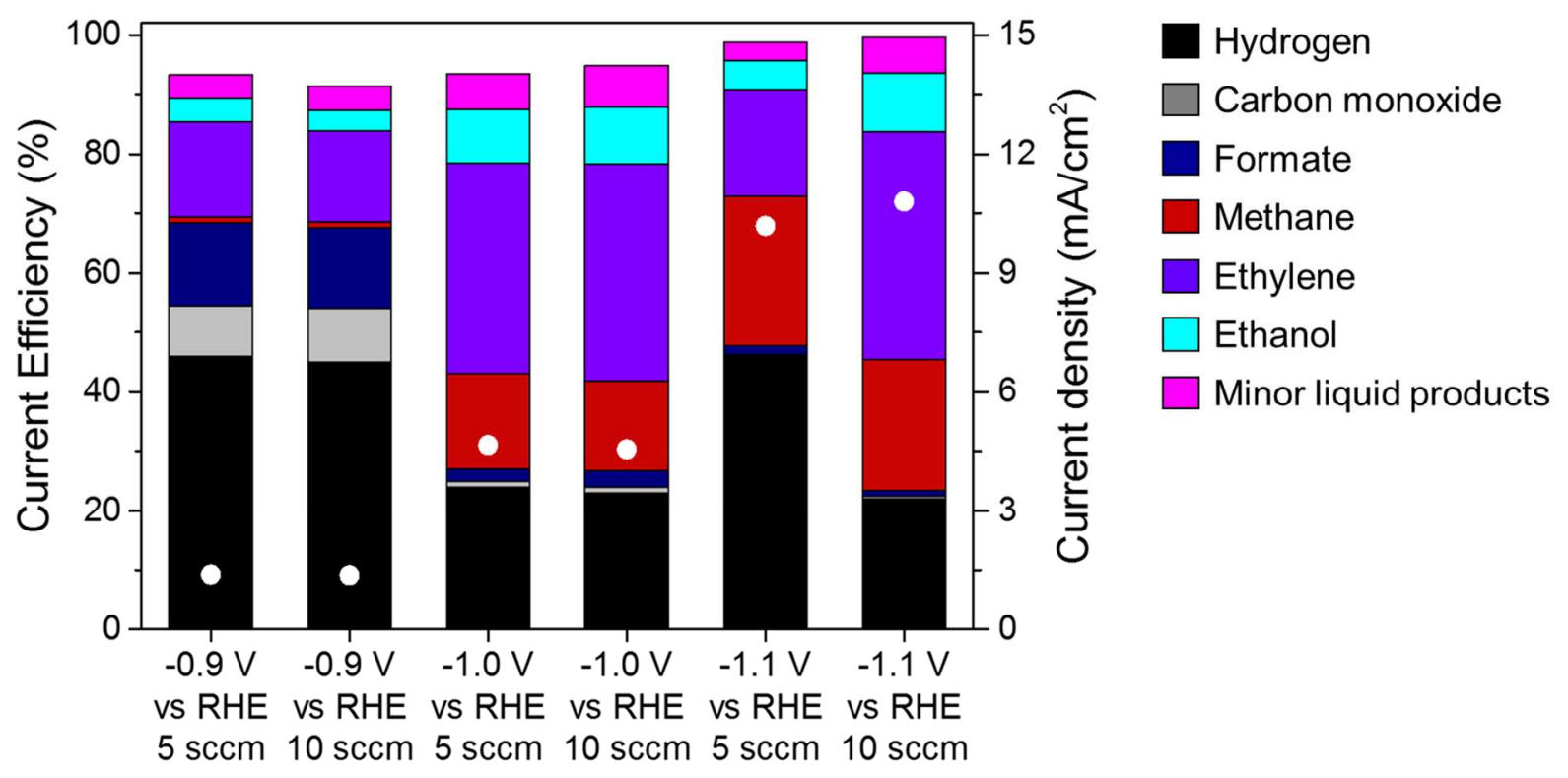

Figure 4: $\mathrm{CO}_{2}$ flow rate studies for probing external mass transport limitations: Current efficiency (bars) and total current density (dots) for $\mathrm{CO}_{2}$ reduction over $\mathrm{Cu}(100)$ at different flow rates of $\mathrm{CO}_{2}$. 
a
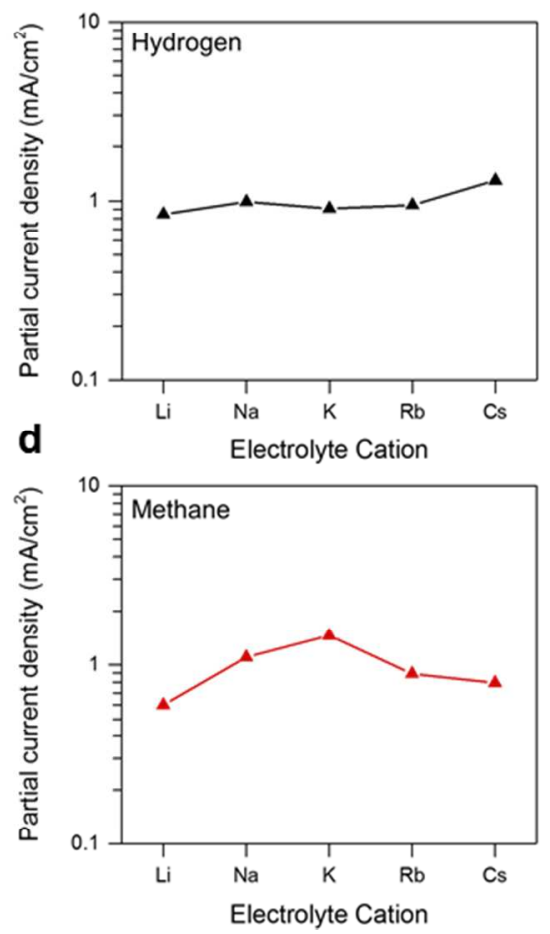

b
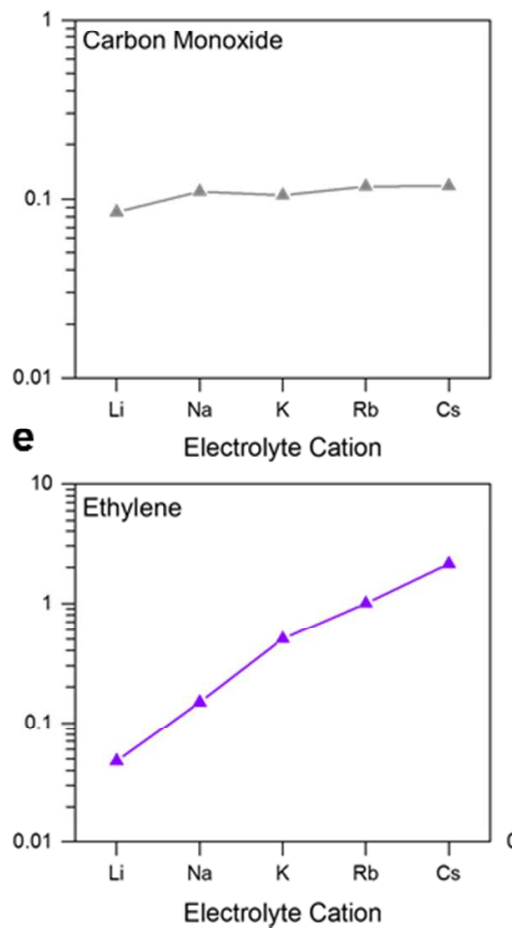

C

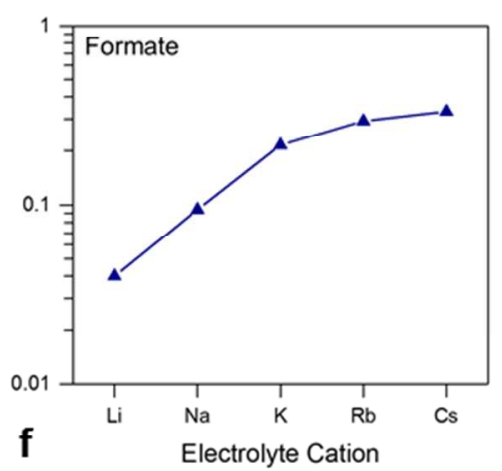

Ethanol

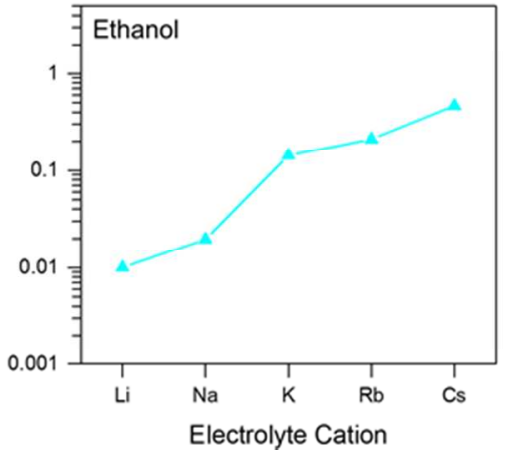

Figure 5: Cation effect on the rates of formation of major products of $\mathrm{CO}_{2}$ reduction over $\mathrm{Cu}(111)$. Partial current densities for each of the major products as a function of the electrolyte metal cation on $\mathrm{Cu}(111)$. Data are presented for the potential of $-1.0 \mathrm{~V}$ vs RHE.

The effects of cation size were also investigated for $\mathrm{CO}_{2}$ reduction over a $\mathrm{Cu}(111)$ surface and the results are presented in Fig. 5. The trends with increasing cation size for the close-packed $\mathrm{Cu}(111)$ surface are consistent with those observed for the $\mathrm{Cu}(100)$ surface. Partial currents to $\mathrm{HCOO}^{-}, \mathrm{C}_{2} \mathrm{H}_{4}$, and $\mathrm{C}_{2} \mathrm{H}_{5} \mathrm{OH}$ increase with increasing cation size while rates of formation of $\mathrm{H}_{2}, \mathrm{CO}$, and $\mathrm{CH}_{4}$ are less affected by cation size. However, the effect of cation size is more pronounced on the close-packed surface, resulting in high selectivity $(\sim 40 \% \mathrm{FE})$ to $\mathrm{C}_{2} \mathrm{H}_{4}$ in $\mathrm{CsHCO}_{3}$ even on a $\mathrm{Cu}(111)$ surface, which is known to be more selective for producing $\mathrm{CH}_{4}$ than $\mathrm{C}_{2} \mathrm{H}_{4}$ in $\mathrm{K}^{+}$-containing electrolytes. ${ }^{29,31,33-36}$ 

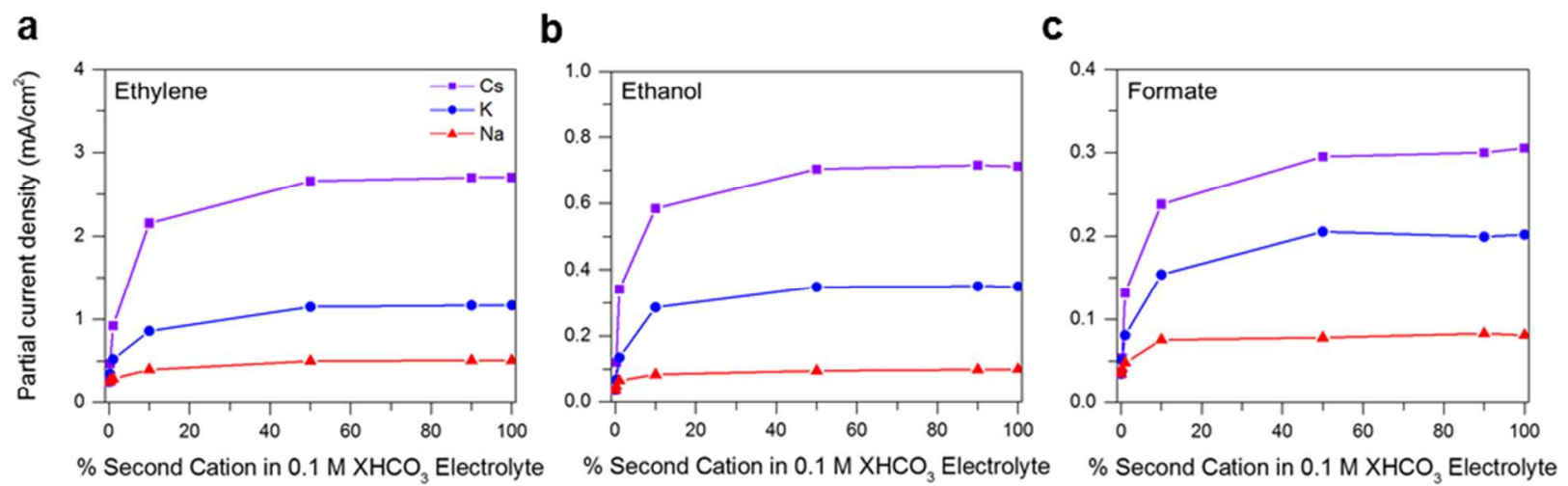

Figure 6: Relative effects of alkali metal cations. Partial currents for ethylene, ethanol, and formate formation as a function of the electrolyte composition on $\mathrm{Cu}(100)$. Data are presented for a potential of $-1.0 \mathrm{~V}$ vs RHE. A mixture of $\mathrm{LiHCO}_{3}$ and $\mathrm{XHCO}_{3}$ electrolyte is used with $\mathrm{X}$ being $\mathrm{Na}, \mathrm{K}, \mathrm{Cs}$ (second cation). A fixed total salinity of $0.1 \mathrm{M}$ was used in all experiments.

\section{Relative effects of alkali metal cations}

To further investigate the effects of the alkali metal cations, electrolysis was performed with mixtures of small $\left(\mathrm{Li}^{+}\right)$and larger $\left(\mathrm{Na}^{+}, \mathrm{K}^{+}, \mathrm{Cs}^{+}\right)$cations in the electrolyte, maintaining the total salinity at 0.1 M. The results are shown in Figure 6. It is evident that the composition of the electrolyte has a noticeable effect on the partial currents for $\mathrm{HCOO}^{-}, \mathrm{C}_{2} \mathrm{H}_{4}$, and $\mathrm{C}_{2} \mathrm{H}_{5} \mathrm{OH}$. No significant effect on the partial currents of $\mathrm{H}_{2}, \mathrm{CO}$, and $\mathrm{CH}_{4}$, was observed. For the latter three products, the effect of the larger cation dominates that of the $\mathrm{Li}^{+}$cation, and even at relatively low percentages of the larger cation. Conversely, an electrolyte mixture that is dilute in the smaller cation results in identical selectivity to a solution that does not contain the small cation. These results suggest that the concentration of larger cations near the cathode surface is larger and/or that the larger cations have a much more significant promotional effect on the production of $\mathrm{C}_{2} \mathrm{H}_{4}, \mathrm{C}_{2} \mathrm{H}_{5} \mathrm{OH}$, and $\mathrm{HCOO}^{-}$. 

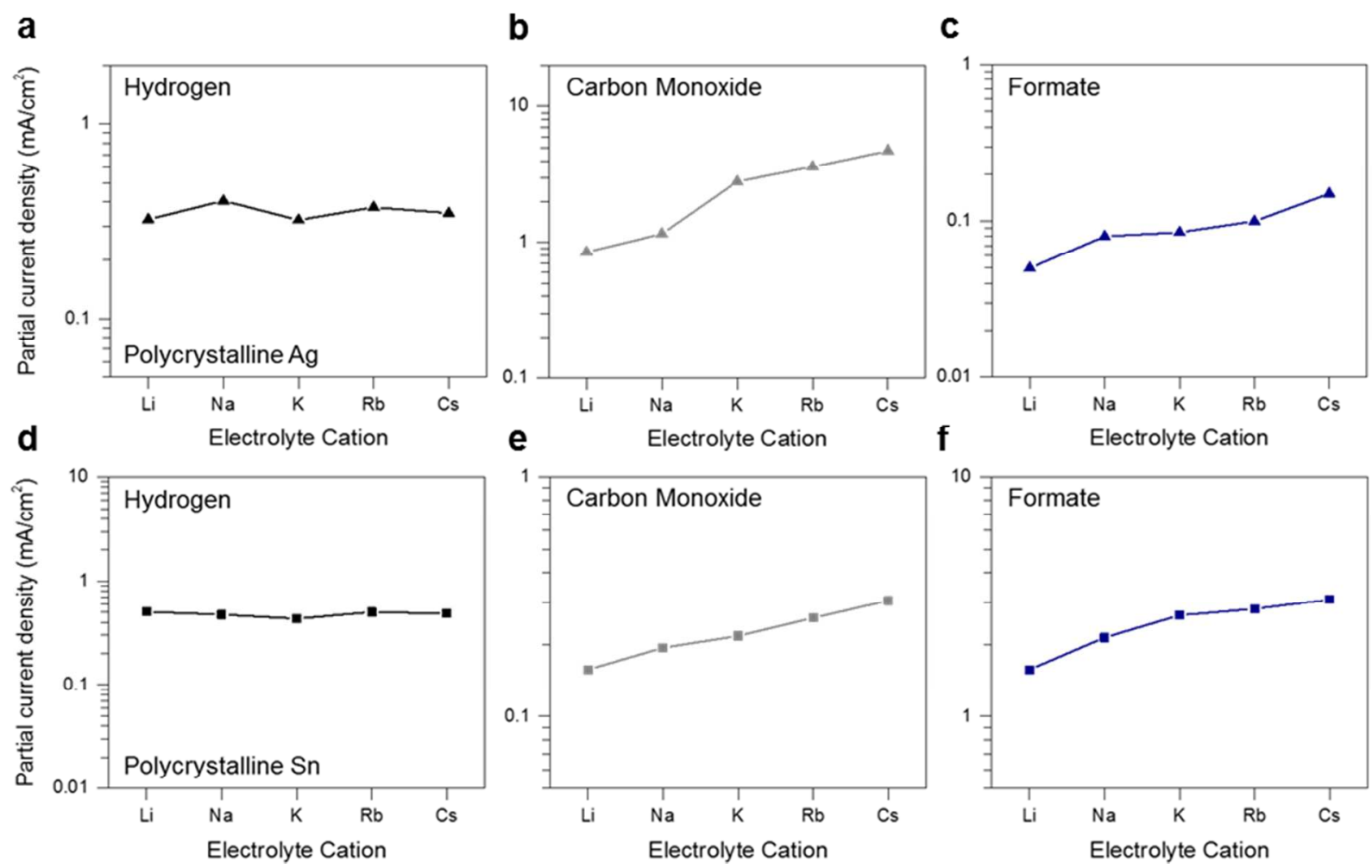

Figure 7: Cation effect on two electron products. Partial currents for each of the major products as a function of the electrolyte metal cation on polycrystalline Ag and Sn. Data are presented for a potential of $-1.0 \mathrm{~V}$ vs RHE.

\section{Cation effect on polycrystalline Ag and $\mathrm{Sn}$}

As carbon monoxide is a reaction intermediate which undergoes further reduction on $\mathrm{Cu}$, the production rate of $\mathrm{CO}$ itself is less straightforward to interpret than that of the other major products. ${ }^{37}$ Therefore, to investigate the effect of cation size on $\mathrm{CO}$ production, and to provide further insights into the trends observed for $\mathrm{Cu}(100)$ and $\mathrm{Cu}(111)$, experiments were conducted on polycrystalline $\mathrm{Ag}$ and $\mathrm{Sn}$ foils - metals that selectively produce $\mathrm{CO}$ and $\mathrm{HCOO}^{-}$, respectively. ${ }^{3,38}$ As seen in Fig. 7, the current densities for $\mathrm{CO}$ and $\mathrm{HCOO}^{-}$production on both metals increases with cation size. This suggests that increasing cation size facilitates activation of $\mathrm{CO}_{2}$. Here again, we see that as with $\mathrm{Cu}(100)$ and $\mathrm{Cu}(111)$, the rate of $\mathrm{H}_{2}$ evolution is unaffected by cation size. These trends are also consistent with previous literature reports. ${ }^{8-11,13,39}$ 
a
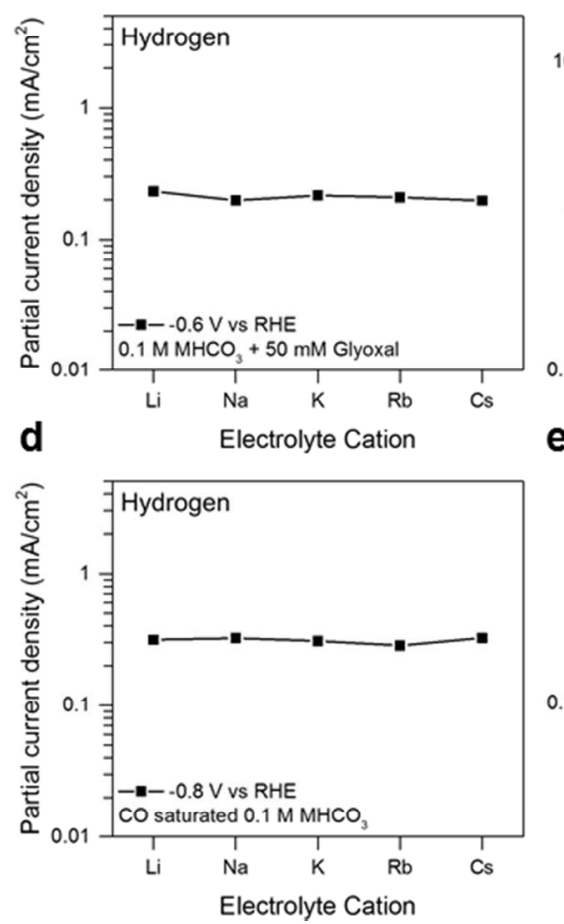

b

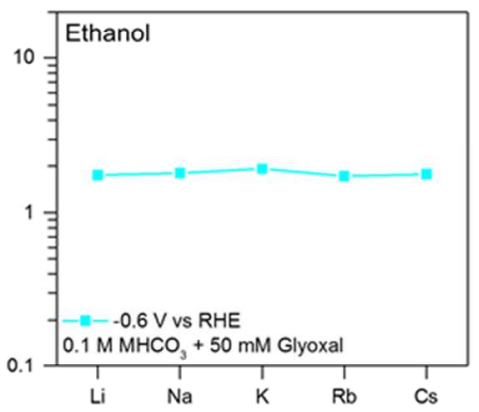

e

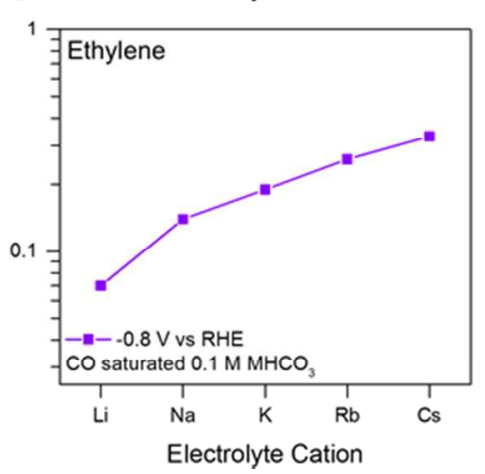

C

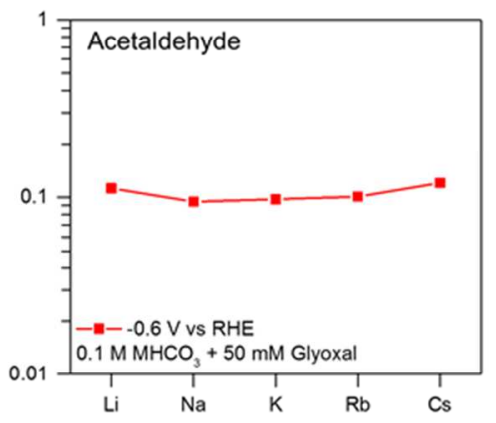

f

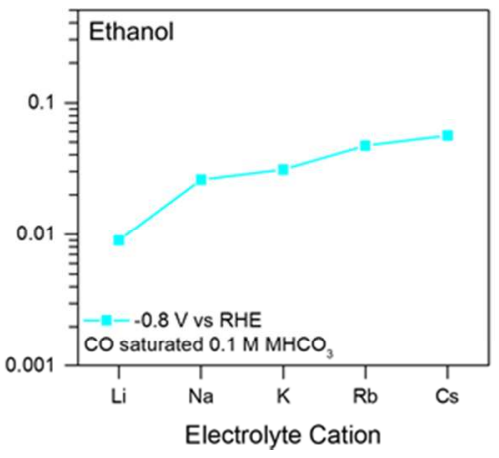

Figure 8: Cation effects of the reduction of reaction intermediates. a-c) Partial currents for hydrogen, ethanol, and acetaldehyde formation from the reduction of glyoxal on $\mathrm{Cu}(100)$. Data is presented at a potential of $-0.6 \mathrm{~V}$ vs RHE. d-f) Partial currents for hydrogen, ethylene, and ethanol formation from the reduction of $\mathrm{CO}$ on $\mathrm{Cu}(100)$. Data is presented at a potential of $-0.8 \mathrm{~V}$ vs RHE.

\section{Cation effects on elementary reaction steps: reduction of intermediates}

As shown above, the size of the electrolyte cation influences the formation of $\mathrm{C}_{2}$ products. Recent theoretical studies suggest that $\mathrm{C}-\mathrm{C}$ bonds are formed via the reaction of two molecules of adsorbed $\mathrm{CO}$ or by the reaction of adsorbed $\mathrm{CO}$ with a formyl group, $\mathrm{HCO} .{ }^{40} \mathrm{~A}$ recent study has shown that the latter process dominates at applied potentials near $-1 \mathrm{~V}$ and leads to the formation of adsorbed $\mathrm{HC}(\mathrm{O})-\mathrm{C}(\mathrm{O})$ species, which then undergoes hydrogenation to form $\mathrm{C}_{2} \mathrm{H}_{4}$ or $\mathrm{CH}_{3} \mathrm{CHO}$ and $\mathrm{C}_{2} \mathrm{H}_{5} \mathrm{OH} .{ }^{40}$ Experimental studies suggest that the precursor to $\mathrm{CH}_{3} \mathrm{CHO}$ and $\mathrm{C}_{2} \mathrm{H}_{5} \mathrm{OH}$ is glyoxal $(\mathrm{OHC}-\mathrm{CHO}) .{ }^{41}$ Therefore, to investigate which steps in the formation of $\mathrm{C}_{2}$ products are affected by the electrolyte cation size, we carried out experiments in electrolyte containing glyoxal. As shown in Figure 8, cation size has no effect on the partial currents of $\mathrm{CH}_{3} \mathrm{CHO}$ and $\mathrm{C}_{2} \mathrm{H}_{5} \mathrm{OH}$ formation, which in this case require no $\mathrm{C}-\mathrm{C}$ bond 
formation as glyoxal is the starting reagent. Consistent with previous observations, no $\mathrm{C}_{2} \mathrm{H}_{4}$ was observed during the hydrogenation of glyoxal. ${ }^{41}$ These findings strongly suggest that the size of the electrolyte cation affects the rate of $\mathrm{C}-\mathrm{C}$ bond formation, the rate increasing with increasing cation size, but has a negligible effect on the hydrogenation of glyoxal to $\mathrm{CH}_{3} \mathrm{CHO}$ and $\mathrm{C}_{2} \mathrm{H}_{5} \mathrm{OH}$.

As larger cations facilitate $\mathrm{CO}_{2}$ activation, evidenced by the increase in rates to $\mathrm{CO}$ and $\mathrm{HCOO}^{-}$ (see Figure 3), experiments were carried out in electrolyte solutions saturated with $\mathrm{CO}$ but free of dissolved $\mathrm{CO}_{2}$, in order to assess whether an increase in the surface coverage of adsorbed $\mathrm{CO}$ relative to adsorbed $\mathrm{H}$ favors $\mathrm{C}-\mathrm{C}$ coupling. Consistent with the results for $\mathrm{CO}_{2}$ reduction over $\mathrm{Cu}(100)$, no change in methane activity with cation size was observed from CO reduction at $-1 \mathrm{~V}$ vs RHE. Figure $8 \mathrm{~b}$ clearly shows that the rates of $\mathrm{C}_{2} \mathrm{H}_{4}$ and $\mathrm{C}_{2} \mathrm{H}_{5} \mathrm{OH}$ formation increase with increasing cation size. We note that the magnitude of this effect is comparable to that observed during the reduction of $\mathrm{CO}_{2}$, which shows that the effect of cation size on the formation of multicarbon products cannot be ascribed solely to more facile $\mathrm{CO}_{2}$ activation.

\section{Discussion \\ Cation promoter effects}

The data presented in this study demonstrate that the size of the alkali metal cations in the electrolyte affects the intrinsic rates of formation of certain reaction products. $\mathrm{On} \mathrm{Cu}(100)$ and $\mathrm{Cu}(111)$, these effects are most notable for $\mathrm{HCOO}^{-}, \mathrm{C}_{2} \mathrm{H}_{4}$, and $\mathrm{C}_{2} \mathrm{H}_{5} \mathrm{OH}$; over polycrystalline $\mathrm{Ag}$ and $\mathrm{Sn}$, the effects of cation size are observed for the formation of $\mathrm{CO}$ and $\mathrm{HCOO}^{-}$. It is also shown that larger cations have a stronger effect than smaller cations, and that only a small fraction of the larger cation is needed in the electrolyte to observe its influence. Trends in the partial current densities derived from the studies of the reduction of key reaction intermediates $(\mathrm{OHCCHO}$ and $\mathrm{CO})$ suggest that the elementary steps promoted by the presence of metal cations are the activation of $\mathrm{CO}_{2}$ and the initial $\mathrm{C}-\mathrm{C}$ coupling, whether through 
$\mathrm{CO}$ dimerization or $\mathrm{CO}-\mathrm{CHO}$ coupling, and not the hydrogenation of $\mathrm{C}_{2}$ intermediates leading to ethylene and ethanol.

We propose that the energetics for the formation of $\mathrm{HCOO}^{-}$and $\mathrm{C}_{2}$ products are influenced by the presence of hydrated alkali ions located at the edge of the Helmholtz plane, and that the observed effects of cation size are attributable to differences in the cation concentration in the outer Helmholtz plane. This explanation is supported by DFT calculations performed using minimum energy structures of solvated cations at the interface. Since both $\mathrm{Cu}(100)$ and $\mathrm{Cu}(111)$ surfaces show consistent trends in activity with respect to alkali cation size, the close-packed $\mathrm{Cu}(111)$ surface was chosen for the DFT simulations, which has also been frequently used in previous theoretical $\mathrm{CO}_{2} \mathrm{R}$ studies ${ }^{42-45}$ and where the water structure is more well-defined. ${ }^{46}$

Because the potentials applied during $\mathrm{CO}_{2}$ reduction are much more negative than the potential of zero charge (PZC) of the low-index facets of $\mathrm{Cu} \sim-0.7 \mathrm{~V}_{\mathrm{SHE}}{ }^{47}$, solvated cations should accumulate near the surface of the electrode during reaction. ${ }^{40,48}$ Given the very negative reduction potentials of alkali ions, they do not chemisorb under $\mathrm{CO}_{2}$ reduction conditions. There is also evidence from studies of oxygen reduction that the cations remain partially solvated at the interface. ${ }^{49}$ The presence of the cation at the metal surface gives rise to high electric fields of $\sim-1 \mathrm{~V} / \AA$ in the vicinity of the ion. ${ }^{25,}{ }^{50}$ In contrast to classical continuum models of the electrochemical interface, the fields are highly localized when the structure of the cation and solvating waters is modeled explicitly. Refs. ${ }^{25,50}$ show that such fields extend roughly $5 \AA$ from the center of the solvated cations and outside of this region decay to zero.

The strength of the adsorbate-field interaction can be probed qualitatively by the application of a uniform field in vacuum. This approach circumvents the challenge of finding a global minimum in the water and solvated cation structure in the presence of various adsorbates on the surface, which introduces many more degrees of freedom than standard atomistic computations in heterogeneous catalysis. It has also been shown previously that the effect of alkali promoters in heterogeneous catalysis can be modeled 
approximately by the effect of a uniform field. ${ }^{51}$ The interaction energy between an adsorbate and a uniform electric field at the interface is given by $^{52}$

$$
\Delta E=\mu \epsilon-\frac{1}{2} \alpha \epsilon^{2}+\cdots
$$

where $\mu$ and $\alpha$ are the dipole moment and the polarizability (respectively) of the adsorbate, and $\varepsilon$ represents the electric field. Adsorbate dipoles oriented in the opposite direction of the field will be stabilized, and vice versa.

Figure 9 shows the field stabilization for various adsorbates that have been proposed to be involved in the electrochemical reduction of $\mathrm{CO}_{2}$ on $\mathrm{Cu}(111) .{ }^{43,49,52}$ The change in adsorption free energy for each species was determined by applying a uniform field oriented perpendicular to the surface in vacuum. ${ }^{43}$ The corresponding values of $\mu$ and $\alpha$, determined by fitting Eq. (1) the calculated data, are given in Table 1 . We note that $\mathrm{H}^{*}$ does not have a significant value of $\mu$ and is not affected by the electric field, which is consistent with previous experimental studies that have shown that hydrogen adsorption is unaffected by the identity of the cation in solution. ${ }^{14-16}$ Since the energy for hydrogen adsorption is a descriptor for the hydrogen evolution activity on metals, the rate for hydrogen production should also be relatively insensitive to the identity of the cation, consistent with the experimental data presented here. ${ }^{53}$ Recent calculations of the electrochemical barriers for $\mathrm{CO}_{2}$ reduction using an explicit solvent model have shown that reduction of $* \mathrm{CO}$ to form ${ }^{*} \mathrm{CHO}$ is the limiting step for $\mathrm{CH}_{4}$ formation. ${ }^{43}$ Since the value of $\mu$ for $* \mathrm{CHO}$ is zero, the cation-induced field would stabilize * $\mathrm{CO}$ and therefore increase the energy barrier for hydrogenation to ${ }^{*} \mathrm{HCO}$, the rate-limiting step on the path to $\mathrm{CH}_{4}$ formation. Therefore, $\mathrm{CH}_{4}$ formation should occur in regions of the catalyst that are not strongly influenced by the cations located at the outer Helmholtz plane, and correspondingly the partial current density for $\mathrm{CH}_{4}$ should not be strongly affected by cation identity, which is consistent with the trend in the experimental data shown above. 


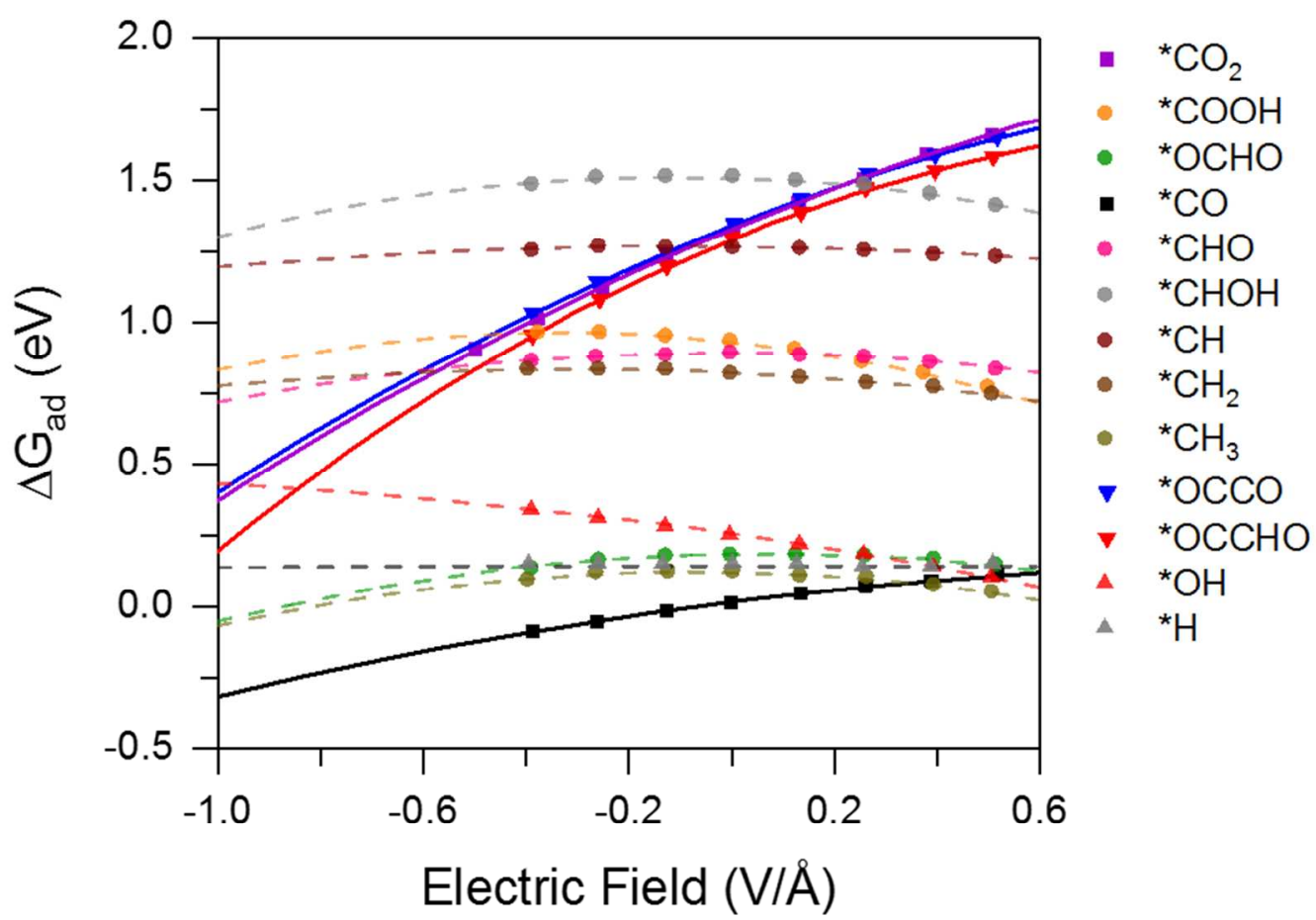

Figure 9: Field effects on various $\mathrm{CO}_{2} \mathrm{R}$ intermediates on $\mathrm{Cu}(111)$. The energy of each adsorbate is plotted as a function of field strength, which is obtained by applying a uniform electric field oriented perpendicular to the slab. The curves are fit to Equation (1) and the corresponding dipole moment $\mu$ and polarizability $\alpha$ of the adsorbates are given in Table 1 . Solid curves highlight the adsorbates that are most strongly affected by an electric field. Adsorbates with positive dipole moments $\mu$ (oriented in the direction opposite to the electric field) are stabilized, while adsorbates with negative $\mu$ (aligned with the electric field) are destabilized.

Table 1 Dipole moments and polarizabilities of adsorbates on $\mathrm{Cu}(111)$, determined with Eq. (1)

\begin{tabular}{lcc}
\hline Adsorbate & $\mu(\mathrm{e} \AA)$ & $\alpha\left(\mathrm{e} \AA^{2} / \mathrm{V}\right)$ \\
\hline${ }^{*} \mathrm{CO}_{2}$ & 0.76 & 0.40 \\
$* \mathrm{COOH}$ & -0.19 & 0.60 \\
$* \mathrm{OCHO}$ & 0.04 & 0.42 \\
$* \mathrm{CO}$ & 0.23 & 0.22 \\
$* \mathrm{CHO}$ & 0.00 & 0.36 \\
$* \mathrm{OCCO}$ & 0.66 & 0.54 \\
$* \mathrm{OCCHO}$ & 0.75 & 0.74 \\
$* \mathrm{CHOH}$ & -0.05 & 0.52 \\
$* \mathrm{CH}$ & -0.02 & 0.18 \\
$* \mathrm{CH}$ & -0.08 & 0.26 \\
$* \mathrm{CH}$ & -0.03 & 0.44 \\
$* \mathrm{OH}$ & -0.26 & 0.14 \\
$* \mathrm{H}$ & 0.00 & 0.00 \\
\hline
\end{tabular}


For adsorbates containing $\mathrm{C}=\mathrm{O}$ bonds oriented perpendicular to the surface - in particular, ${ }^{*} \mathrm{CO}_{2}$, *OCCO, and *OCCHO — the field stabilization should be large, $\sim 1 \mathrm{eV}$ for fields of $\sim-1 \mathrm{~V} / \AA$ in the vicinity of the cations. As shown in Table 1, these species have the largest dipole moments. Previous theoretical calculations have shown that on weakly binding metals such as $\mathrm{Ag}$, the field-induced stabilization of $* \mathrm{CO}_{2}$ is crucial for the activation of $\mathrm{CO}_{2}$ to form $\mathrm{CO}^{25}$ The barrier for the hydrogenation of $* \mathrm{CO}_{2}$ to $* \mathrm{COOH}$ is generally very small, ${ }^{54}$ so stabilization of $* \mathrm{CO}_{2}$ should increase the coverage of ${ }^{*} \mathrm{COOH}$. The ${ }^{*} \mathrm{COOH}$ species can undergo further hydrogenation to form $\mathrm{HCOOH}$ or ${ }^{*} \mathrm{CO}$. The chemical hydrogenation barriers for $* \mathrm{COOH}$ to form $\mathrm{HCOOH}$ are surmountable at $0.69 \mathrm{eV}$ and $0.75 \mathrm{eV}$ on $\mathrm{Cu}(111)$ and $\mathrm{Cu}(211)$ respectively, and $0.46 \mathrm{eV}$ on $\mathrm{Ag}(211),{ }^{23}$ consistent with increased $\mathrm{HCOOH}$ production observed on all of the surfaces investigated. For weakly binding metals such as $\mathrm{Ag}$ and $\mathrm{Sn}$, the field effect would promote $\mathrm{CO}_{(\mathrm{g})}$ production, whereas for moderate to strongly binding metals such as $\mathrm{Cu}$ and $\mathrm{Pt},{ }^{*} \mathrm{CO}$ produced in the vicinity of a cation would also be field stabilized, thereby decreasing its desorption rate and increasing its ${ }^{*} \mathrm{CO}$ coverage there.

On $\mathrm{Cu}$ surfaces, formation of the initial intermediates to $\mathrm{C}_{2}$ products are also field-assisted. The greater stabilization of the $* \mathrm{OCCO}$ relative to $2 * \mathrm{CO}$ in the presence of a cation is due to the differences in the dipole moments of the product and reactant species, ${ }^{36}$ which has the effect of lowering the barrier to $\mathrm{C}-\mathrm{C}$ bond formation. In the absence of the cation-created electrostatic field and effects of solvation by water, the barrier for this process is not surmountable at room temperature.$^{55}$ At higher overpotentials, where $* \mathrm{CHO}$ can be produced, ${ }^{*} \mathrm{CO}-{ }^{*} \mathrm{CHO}$ coupling would also be a feasible route towards $\mathrm{C}_{2}$ products, and the corresponding barrier should be similarly field-stabilized due to the large dipole on *OCCHO, as shown in Figure $9 .^{40}$ Since the formation of glyoxal via addition of a hydrogen atom to *OCCHO is the first step along the path to forming ethylene and ethanol, the observation (see Figure 8) that the selectivity of products derived from glyoxal is independent of cation size suggests that the rate-determining step in formation of $\mathrm{C}_{2}$ products occurs at the point of $\mathrm{C}-\mathrm{C}$ bond formation and prior to formation of glyoxal. ${ }^{54}$ 
The net effect of increased $\mathrm{CO}$ production, $\mathrm{CO}$ coverage and $\mathrm{C}-\mathrm{C}$ coupling on $\mathrm{Cu}$ on field-stabilized sites results in a net non-monotonic trend in the partial current density for $\mathrm{CO}$ with cation size.

While the influence of the cation-induced field at the catalyst surface can explain the role of cations in promoting elementary steps in the reduction of $\mathrm{CO}_{2}$ that involve strong dipole moments, it does not explain the observed trend with cation size. We therefore explored the possibilities that this effect is due to disparities in the magnitude of the electrostatic field induced by cations of different size and/or an increase in the concentration of solvated cations at the outer Helmholtz plane as a function of size.

Constrained minima hopping ${ }^{26}(\mathrm{CMH})$ was used to obtain the optimized structure of water surrounding each solvated ion on $\mathrm{Cu}(111)$. The structures of the solvated ions are shown in Figure S5 and the distances of the solvated cation from the $\mathrm{Cu}(111)$ surface are given in Table S3. Figure 10 shows that the calculated fields in the vicinity of adsorbed $\mathrm{CO}(* \mathrm{CO})$ do not show a systematic variation with cation size. Moreover, any differences in the binding energy of intermediates induced by cations would give rise to exponential differences in current density, which we do not observe.

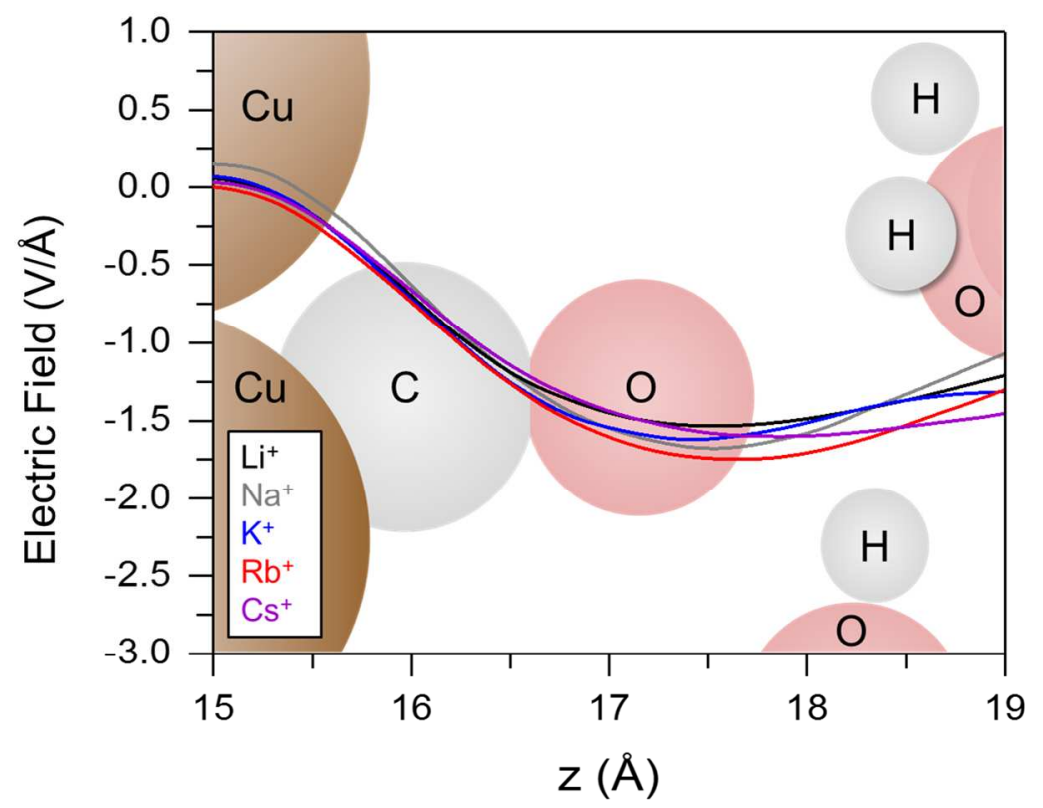

Figure 10. Electric field distribution near the center of the adsorbate plotted as a function of the $z$ coordinate of the simulation cell for the $2 * \mathrm{CO}$ initial state. The geometry of an example structure is overlaid to clearly illustrate the position of the adsorbate. The cell is viewed from the side and rotated 
$90^{\circ}$. The minimum $z$ value is taken at the $\mathrm{Cu}$ surface and the $z$-position of the solvated cations is roughly at $20 \AA$ and not included in the overlay.

We hypothesize, therefore, that the ion specificity arises from an increase in the concentration of cations at the outer Helmholtz plane with increasing cation size. To determine the driving force for each cation toward the Helmholtz plane from bulk solution, we used these globally optimized solvation structures for each cation (Table S3) and calculated the energy required to move a solvated cation from the bulk of the electrolyte to a fixed distance of $6.25 \AA$ above the $\mathrm{Cu}(111)$ surface the (see the SI for details). Figure 11 shows this energy change with the cathode potential relative to that for $\mathrm{Li}^{+}, \Delta \Delta E$. The potential $U$ vs SHE is determined through:

$$
U=\frac{\Phi-\Phi_{S H E}}{e}
$$

where $\Phi$ is the work function of the interface and $\Phi_{S H E}$ is that corresponding to the standard hydrogen electrode, determined experimentally to be $\sim 4.4 \mathrm{eV} .{ }^{56}$ The value of $\Delta \Delta E$ becomes more negative with increasing cation size, its magnitude increasing in the order $\mathrm{Li}^{+}<\mathrm{Na}^{+}<\mathrm{K}^{+}<\mathrm{Rb}^{+}<\mathrm{Cs}^{+}$. Therefore, the driving force for each cation to be at the Helmholtz plane relative to the bulk electrolyte increases with cation size. This trend suggests that the concentration of cations at the outer Helmholtz plane should increase with increasing cation size, leading to increased product current densities. Consistent with this reasoning, we observed (see Figure 6) that at a constant cation concentration, replacement of even a small fraction of $\mathrm{Li}^{+}$by $\mathrm{Cs}^{+}$results in a shift in the product distribution from one characteristic for $\mathrm{Li}^{+}$to one characteristic for $\mathrm{Cs}^{+}$. This supports the hypothesis that there is a stronger driving force for $\mathrm{Cs}^{+}$to be at the Helmholtz plane compared to $\mathrm{Li}^{+}$. Without this stronger driving force on $\mathrm{Cs}+$ to be in the Helmholtz plane, the trends in Figure 6 would be linear. 


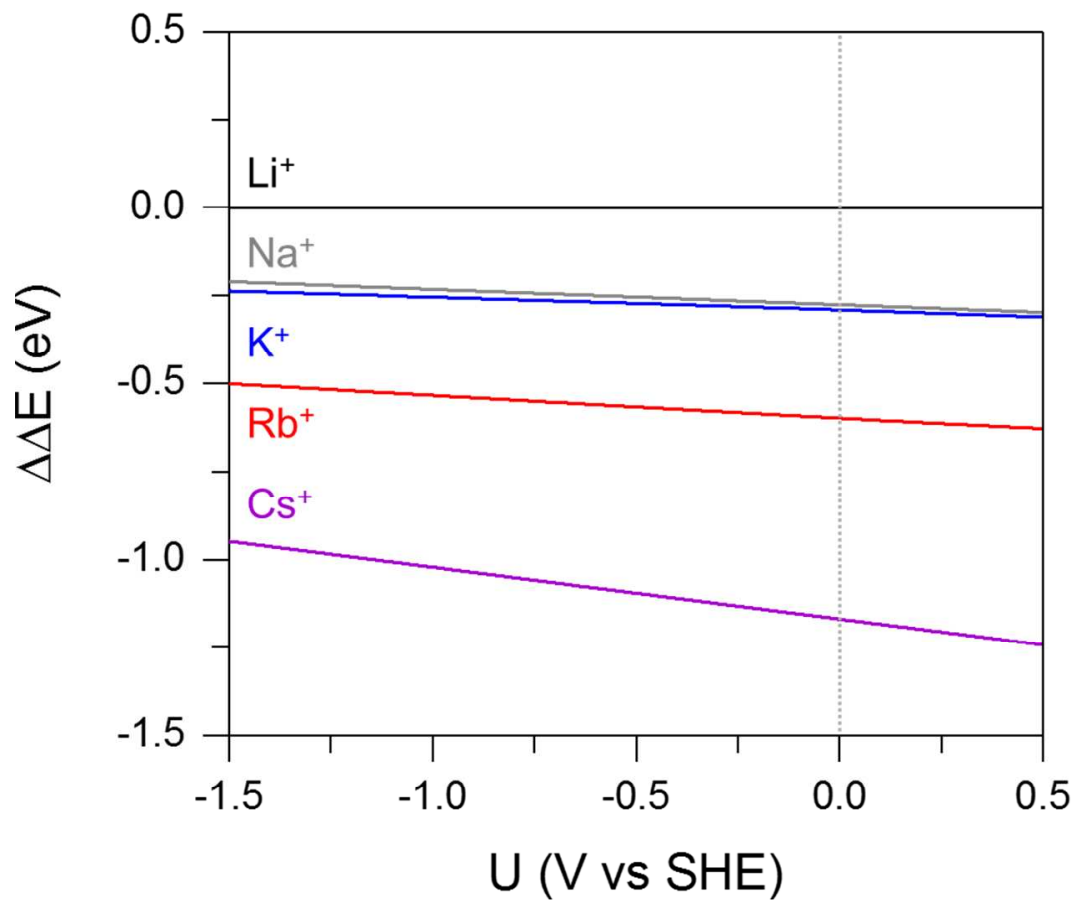

Figure 11: The change in energy for bringing a solvated cation from bulk electrolyte to the outer Helmholtz plane at the $\mathrm{Cu}(111)$ facet for different cations shown as a function of the standard hydrogen electrode (SHE) potential. All energies are referenced to that for the $\mathrm{Li}^{+}$cation. The dependence of these energies on cathode potential results from the partial electron transfer to the ion upon migration from the bulk to the Helmholtz plane, and is reflected in Eq. 5. This energy becomes more negative with increasing ion size, suggesting a greater concentration of larger cations in the outer Helmholtz plane and giving rise to increased product current densities. The vertical dotted line indicates the potential for the standard hydrogen electrode.

\section{Conclusions}

The present study investigated the effects of electrolyte cation size on the activity and selectivity of metal catalysts used for the electrochemical reduction of $\mathrm{CO}_{2}$. The experimental work was conducted under conditions where the influence of electrolyte concentration polarization was negligible in order to avoid the additional influence of changes in $\mathrm{pH}$ and the consequent effects on the concentration of $\mathrm{CO}_{2}$ near the cathode surface. For polycrystalline $\mathrm{Ag}$ and $\mathrm{Sn}$, increasing the size of the alkali metal cation in the electrolyte increases the partial current densities for $\mathrm{HCOO}^{-}$and $\mathrm{CO}$, but has no effect on the partial current density for $\mathrm{H}_{2}$. Similar experiments conducted using $\mathrm{Cu}(100)$ and $\mathrm{Cu}(111)$ oriented films 
deposited on crystalline $\mathrm{Si}(100)$ and(111) surfaces show an increase in the current densities for HCOO', $\mathrm{C}_{2} \mathrm{H}_{4}$, and $\mathrm{C}_{2} \mathrm{H}_{5} \mathrm{OH}$ but little to no effect on the partial current densities for $\mathrm{H}_{2}, \mathrm{CO}$, and $\mathrm{CH}_{4}$ as the size of the electrolyte cation is increased.

The observed effects are interpreted on the basis of DFT calculations. Hydrated alkali metal cations in the outer Helmholtz plane create a dipole field of the order $1 \mathrm{~V} / \AA \AA$, which can stabilize the adsorption of surface intermediates having significant dipole moments (e.g., ${ }^{*} \mathrm{CO}_{2},{ }^{*} \mathrm{CO},{ }^{*} \mathrm{OCCO}$ ). This field stabilization decreases the energy for the reduction of $* \mathrm{CO}_{2}$ adsorption, the precursor to two-electron products, and C-C coupling to form * $\mathrm{OCCO}$ or * OCCHO, the precursor to $\mathrm{C}_{2} \mathrm{H}_{4}$ and $\mathrm{C}_{2} \mathrm{H}_{5} \mathrm{OH}$. Calculations of the stability of the solvated cation in the Helmholtz plane indicate that larger hydrated cations are more energetically favored at the outer Helmholtz plane than smaller ones, which suggest a larger coverage of cations as cation size increases. This result is consistent with the experimental observation that a small percentage of larger cations has a large effect on product distribution.

These findings are consistent with the trends in partial current for $\mathrm{C}_{1}$ products observed on polycrystalline $\mathrm{Ag}$ and $\mathrm{Sn}$ and on $\mathrm{Cu}(100)$ and $\mathrm{Cu}(111)$ surfaces, and for $\mathrm{C}_{2}$ products observed on $\mathrm{Cu}(100)$ and $\mathrm{Cu}(111)$ surfaces. Also consistent with the conclusions drawn from the theoretical analysis is that cation size affects the partial currents for $\mathrm{C}_{2} \mathrm{H}_{4}$ and $\mathrm{C}_{2} \mathrm{H}_{5} \mathrm{OH}$ produced during the electrochemical reduction of $\mathrm{CO}$ over $\mathrm{Cu}(100)$ but has no influence on formation of these products upon reduction of glyoxal. The absence of cation size effect on the partial current for $\mathrm{H}_{2}$ produced on $\mathrm{Ag}, \mathrm{Sn}, \mathrm{Cu}(100)$, and $\mathrm{Cu}(111)$ is attributed to the absence of a dipole for ${ }^{*} \mathrm{H}$. Similarly, no effect of cation size on the formation of $\mathrm{CH}_{4}$ on $\mathrm{Cu}(100)$ and $\mathrm{Cu}(111)$ surfaces is expected since the field of a cation would tend to stabilize *CO more than ${ }^{*} \mathrm{CHO}$, thereby increasing the energy for $* \mathrm{CO}$ hydrogenation to ${ }^{*} \mathrm{CHO}$, the rate-limiting step leading to $\mathrm{CH}_{4}$.

Finally, we note that differences in the effects of electrolyte cation size on the formation of $\mathrm{CO}$ on $\mathrm{Ag}$ and $\mathrm{Sn}$ vs. $\mathrm{Cu}(100)$ and $\mathrm{Cu}(111)$ are attributable to the following considerations. For $\mathrm{Ag}$ and $\mathrm{Sn}, \mathrm{CO}$ is a final product, and therefore only influenced by its formation by hydrogenation of * $\mathrm{COOH}$ which 
should have an increased coverage from the field-stabilization of $* \mathrm{CO}_{2}$. In contrast, for $\mathrm{Cu}(100)$ and $\mathrm{Cu}(111),{ }^{*} \mathrm{CO}$ is an intermediate in the formation of $\mathrm{CH}_{4}$. Since the dipole electrostatic field created by hydrated cations accelerates both the formation and consumption of $* \mathrm{CO}$, there is no observable effect of cation size on the partial current for $\mathrm{CO}$ on $\mathrm{Cu}(100)$ and $\mathrm{Cu}(111)$.

\section{Acknowledgements}

This material is based upon work performed by the Joint Center for Artificial Photosynthesis, a DOE Energy Innovation Hub, supported through the Office of Science of the U.S. Department of Energy under Award Number DE-SC0004993. J.R. gratefully acknowledges support of the National Science Foundation Graduate Research Fellowship Program (NSF GRFP) under Grant No. DGE-0802270. The authors would also like to acknowledge the allocation of computer time at the National Energy Research Scientific Computing Center, a DOE Office of Science User Facility supported by the Office of Science of the U.S. Department of Energy under Contract No. DE-AC02-05CH11231.

\section{References}

1. Lewis, N. S.; Nocera, D. G. Proc. Natl. Acad. Sci. 2006, 103, 15729-15735.

2. $\quad$ Chu, S.; Majumdar, A. Nature 2012, 488, 294-303.

3. Hori, Y., Electrochemical CO2 Reduction on Metal Electrodes. In Modern Aspects of Electrochemistry, Vayenas, C. G.; White, R. E.; Gamboa-Aldeco, M. E., Eds. Springer New York: New York, NY, 2008; 89-189.

4. Kuhl, K. P.; Hatsukade, T.; Cave, E. R.; Abram, D. N.; Kibsgaard, J.; Jaramillo, T. F. J. Am. Chem. Soc. 2014, 136, 14107-14113.

5. $\quad$ Hori, Y.; Wakebe, H.; Tsukamoto, T.; Koga, O. Electrochim. Acta 1994, 39, 1833-1839.

6. $\quad$ Hori, Y.; Murata, A.; Takahashi, R. J. Chem. Soc. Faraday Trans. 1989, 85, 2309-2326.

7. Kuhl, K. P.; Cave, E. R.; Abram, D. N.; Jaramillo, T. F. Energy Environ. Sci. 2012, 5, 7050-7059.

8. Frumkin, A. N. Trans. Faraday Soc. 1959, 55, 156-167.

9. $\quad$ Akira, M.; Yoshio, H. Bull. Chem. Soc. Jpn 1991, 64, 123-127.

10. Thorson, M. R.; Siil, K. I.; Kenis, P. J. A. J. Electrochem. Soc. 2013, 160, 69-74.

11. Paik, W.; Andersen, T. N.; Eyring, H. Electrochim. Acta 1969, 14, 1217-1232.

12. Kaneco, S.; Iiba, K.; Katsumata, H.; Suzuki, T.; Ohta, K. J. Solid State Electrochem. 2007, 11, 490-495. 
13. Singh, M. R.; Kwon, Y.; Lum, Y.; Ager, J. W.; Bell, A. T. J. Am. Chem. Soc. 2016, 138, 1300613012.

14. Subbaraman, R.; Tripkovic, D.; Strmcnik, D.; Chang, K.-C.; Uchimura, M.; Paulikas, A. P.; Stamenkovic, V.; Markovic, N. M. Science 2011, 334, 1256-1260.

15. Stoffelsma, C.; Rodriguez, P.; Garcia, G.; Garcia-Araez, N.; Strmcnik, D.; Marković, N. M.; Koper, M. T. M. J. Am. Chem. Soc. 2010, 132, 16127-16133.

16. Strmcnik, D.; Kodama K.; van der Vliet, D.; Greeley, J.; Stamenkovic, V. R.; Marković, N. M. Nat. Chem. 2009, 1, 466-472.

17. Suntivich, J.; Perry, E. E.; Gasteiger, H. A.; Shao-Horn, Y. Electrocatalysis 2013, 4, 49-55.

18. Angelucci, C. A.; Varela, H.; Tremiliosi-Filho, G.; Gomes, J. F. Electrochem. Comm. 2013, 33, $10-13$.

19. Lobaccaro, P.; Singh, M. R.; Clark, E. L.; Kwon, Y.; Bell, A. T.; Ager, J. W. Phys. Chem. Chem. Phys. 2016, 18, 26777-26785.

20. Giannozzi, P.; Baroni, S.; Bonini, N.; Calandra, M.; Car, R.; Cavazzoni, C.; Ceresoli, D.; Chiarotti, G.; Cococcioni, M.; Dabo, I.; Dal Corso, A.; de Gironcoli, S.; Fabris, S.; Fratesi, G.; Gebauer, R.; Gerstmann, U.; Gougoussis, C.; Kokalj, A.; Lazzeri, M.; Martin-Samos, L.; Marzari, N.; Mauri, F.; Mazzarello, R.; Paolini, S.; Pasquarello, A.; Paulatto, L.; Sbraccia, C.; Scandolo, S.; Sclauzero, G.; Seitsonen, A.; Smogunov, A.; Umari, P.; Wentzcovitch, R. J. Phys. Condens. Mat. 2009, 21.

21. Bahn, S. R.; Jacobsen, K. W. Comput. Sci. Eng. 2002, 4, 56-66.

22. Wellendorff, J.; Lundgaard, K. T.; Møgelhøj, A.; Petzold, V.; Landis, D. D.; Nørskov, J. K.; Bligaard, T.; Jacobsen, K. W. Phys. Rev. B 2012, 85, 235149.

23. Yoo, J. S.; Abild-Pedersen, F.; Nørskov, J. K.; Studt, F. ACS Catal. 2014, 4, 1226-1233.

24. Monkhorst, H.; Pack, J. Phys. Rev. B 1976, 13, 5188-5192.

25. Chen, L. D.; Urushihara, M.; Chan, K.; Nørskov, J. ACS Catal. 2016, 6, 7133-7139.

26. Peterson, A. A. Top. Catal. 2013, 57, 40-53.

27. Hahn, C.; Hatsukade, T.; Kim, Y.-G.; Vailionis, A.; Baricuatro, J. H.; Higgins, D. C.; Nitopi, S. A.; Soriaga, M. P.; Jaramillo, T. F. Proc. Natl. Acad. Sci. 2017, 114, 5918-5923.

28. Jiang, H.; Klemmer, T. J.; Barnard, J. A.; Payzant, E. A. J. Vac. Sci. Tech. A 1998, 16, 33763383.

29. Hori, Y.; Takahashi, I.; Koga, O.; Hoshi, N. J. Phys. Chem. B 2002, 106, 15-17.

30. Schouten, K. J. P.; Qin, Z.; Gallent, E. P.; Koper, M. T. M. J. Am. Chem. Soc. 2012, 134, 98649867.

31. Roberts, F. S.; Kuhl, K. P.; Nilsson, A. ChemCatChem 2016, 8, 1119-1124.

32. Kim, Y.-G.; Baricuatro, J. H.; Javier, A.; Gregoire, J. M.; Soriaga, M. P. Langmuir 2014, 30, 15053-15056.

33. Durand, W. J.; Peterson, A. A.; Studt, F.; Abild-Pedersen, F.; Nørskov, J. K. Surf. Sci. 2011, 605, 1354-1359.

34. Schouten, K. J. P.; Pérez Gallent, E.; Koper, M. T. M. ACS Catal. 2013, 3, 1292-1295.

35. Montoya, J. H.; Shi, C.; Chan, K.; Nørskov, J. K. J. Phys. Chem. Lett. 2015, 6, 2032-2037.

36. Sandberg, R. B.; Montoya, J. H.; Chan, K.; Nørskov, J. K. Surf. Sci. 2016, 654, 56-62.

37. Hori, Y.; Murata, A.; Yoshinami, Y. J. Chem. Soc. Faraday Trans. 1991, 87, 125-128.

38. Hatsukade, T.; Kuhl, K. P.; Cave, E. R.; Abram, D. N.; Jaramillo, T. F. Phys. Chem. Chem. Phys. 2014, 16, 13814-13819.

39. Kyriacou, G. Z.; Anagnostopoulos, A. K. J. Appl. Electrochem. 1993, 23, 483-486.

40. Goodpaster, J. D.; Bell, A. T.; Head-Gordon, M. J. Phys. Chem. Lett. 2016, 7, 1471-1477.

41. Schouten, K. J. P.; Kwon, Y.; van der Ham, C. J. M.; Qin, Z.; Koper, M. T. M. Chem. Sci. 2011, 2, 1902-1909.

42. Akhade, S. A.; McCrum, I. T.; Janik, M. J. J. Electrochem. Soc. 2016, 163, 477-484.

43. Liu, X.; Xiao, J.; Peng, H.; Hong, X.; Chan, K.; Nørskov, J. K. Nat. Comm. 2017, 8, 1543815444. 
44. Shi, C.; Hansen, H. A.; Lausche, A. C.; Nørskov, J. K. Phys. Chem. Chem. Phys. 2014, 16, 47204727.

45. Xiao, H.; Cheng, T.; Goddard, W. A.; Sundararaman, R. J. Am. Chem. Soc. 2016, 138, 483-486.

46. Ogasawara, H.; Brena, B.; Nordlund, D.; Nyberg, M.; Pelmenschikov, A.; Pettersson, L. G. M.;

Nilsson, A. Phys. Rev. Lett. 2002, 89, 276102.

47. Lukomska, A.; Sobkowski, J. J. Electroanal. Chem. 2004, 567, 95-102.

48. Cheng, T.; Xiao, H.; Goddard, W. A. J. Am. Chem. Soc. 2016, 138, 13802-13805.

49. Strmcnik, D.; van der Vliet, D. F.; Chang, K. C.; Komanicky, V.; Kodama, K.; You, H.;

Stamenkovic, V. R.; Marković, N. M. J. Phys. Chem. Lett. 2011, 2, 2733-2736.

50. $\quad$ Montoya, J. H.; Shi, C.; Chan, K.; Norskov, J. K. J. Phys. Chem. Lett. 2015, 6, 2032-2037.

51. Mortensen, J. J.; Hammer, B.; Nørskov, J. K. Phys. Rev. Lett. 1998, 80, 4333-4336.

52. Nørskov, J. K. N.; Studt, F.; Abild-Pedersen, F.; Bligaard, T., Fundamental Concepts in Heterogeneous Catalysis. Wiley, Hoboken, New Jersey: 2014.

53. Nørskov, J. K.; Bligaard, T.; Logadottir, A.; Kitchin, J. R.; Chen, J. G.; Pandelov, S.; Stimming, U. J. Electrochem. Soc. 2005, 152, 23-26.

54. Shi, C.; O'Grady, C. P.; Peterson, A. A.; Hansen, H. A.; Nørskov, J. K. Phys. Chem. Chem. Phys. 2013, 15,7114 .

55. Montoya, J. H.; Peterson, A. A.; Nørskov, J. K. ChemCatChem 2013, 5, 737-742.

56. Trasatti, S. Pure Appl. Chem. 1986, 58.

\section{Table of contents figure}

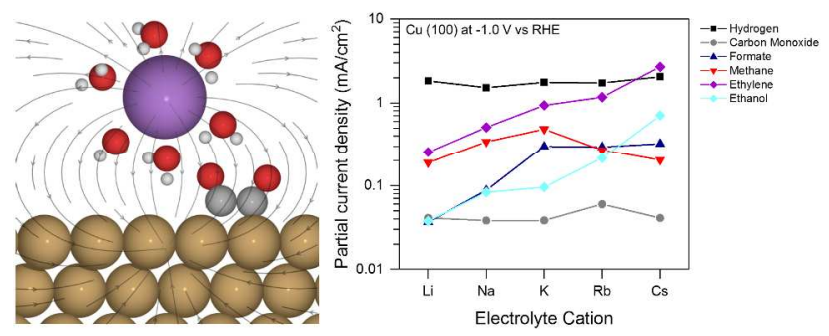

